\title{
Is the pollen-limited mistletoe Peraxilla tetrapetala (Loranthaceae) also seed limited?
}

\author{
DAVE KELLY, ${ }^{1 \star}$ JENNY J. LADLEY ${ }^{1}$ AND ALASTAIR W. ROBERTSON ${ }^{2}$ \\ ${ }^{1}$ Biological Sciences, University of Canterbury, Private Bag 4800, Christchurch, New Zealand (Email: \\ dave.kelly@canterbury.ac.nz), and 2 Ecology, Institute of Natural Resources, Massey University, \\ Palmerston North, New Zealand
}

\begin{abstract}
Seed production in the endemic New Zealand mistletoe Peraxilla tetrapetala (Loranthaceae) has been shown to be consistently pollen limited, but to date there has been no test of whether the species is also seed limited. If it is not seed limited, then pollen limitation may have no effect on population size. We tested for seed limitation by sowing seeds onto host trees at high and low densities at two sites, and following survival for up to 69 months. Our rationale was that unless there is strong density-dependent seedling mortality sufficient to negate increases in seed supply, the species would be seed limited. We simultaneously measured pollen limitation at both sites using pollen augmentation. Peraxilla tetrapetala was strongly pollen limited at both sites over 7 years at Ohau (mean Pollen Limitation Index 0.62), and 12 years at Craigieburn (mean PLI 0.44), before and during the seed-limitation study. There was no significant overall negative effect of density on survival in sown $P$. tetrapetala seeds over 42-69 months. There was a significant positive effect: seeds were more likely to adhere to branches when sown at high densities. This initial advantage to high-density seeds was gradually eroded by slightly (but non-significantly) lower survival rates of adhered seeds at high density. By the end of the study there was no significant difference in overall survival in high and low density plantings. This means that $P$. tetrapetala was apparently both pollen limited and seed limited at both our sites. Hence, reduced densities of native bird pollinators caused by introduced mammalian carnivores are likely to reduce the density of adult mistletoes in the next generation. However, the generality of this result may be affected by the fact that mistletoes do not have a dense 'seedling shadow' under the parent mistletoe.
\end{abstract}

Key words: density dependence, limiting factor, mutualism, pollination, self-thinning.

\section{INTRODUCTION}

Do mutualisms matter? Bond (1994) addressed this question and showed that there were two conditions that had to be met before a mutualism (such as animal pollination of flowers) would affect the chance of extinction of the plant (i.e. plant population size). The first condition is pollen limitation (that the flowers require visits by pollinators, and that too few pollinator visits occur). The second condition is seed limitation (that seed supply limits the numbers of adult plants in the next generation). It is possible that for a given plant the first condition might be met but not the second, because self-thinning (density dependence) often operates at the seedling stage, which might mean that the density of adult plants is insensitive to seed density over quite a wide range of levels of seed production.

Tests for pollen limitation typically use pollen augmentation studies (Ashman et al. 2004), where pollen supply is artificially increased and the effects on fruit set and/or seed set are measured. Studies of pollen limitation often demonstrate that Bond's first condition is

${ }^{\star}$ Corresponding author.

Accepted for publication February 2007. met. For example, Burd (1994) and Knight et al. (2005) both found about $63 \%$ of reviewed studies in a range of plant species showed some pollen limitation (out of 258 and 482 studies, respectively). There are a number of confounding factors that have to be considered when evaluating these results, such as the diversion of resources to treatment flowers from elsewhere on the plant, or trade-offs against future reproduction (Zimmerman \& Pyke 1988; Knight et al. 2006). However, a number of studies have carefully controlled for within-plant resource shifts and convincingly demonstrated pollen limitation (Knight et al. 2005).

Few pollen-limitation studies go on to consider Bond's second factor, and show that plant reproduction is also seed limited (Ashman et al. 2004). The standard test for seed limitation is a seed augmentation experiment. More than half (53\%) of the 100 mainly herbaceous plant species reviewed by Turnbull et al. (2000) showed some evidence for seed limitation. But few studies have considered pollen limitation and seed limitation in the same plant. In fact, in a recent review, Ashman et al. (2004) could not find a single species for which both pollen augmentation and seed augmentation experiments had been performed at the same time. 
Several recent papers (Robertson et al. 1999; Kelly et al. 2004) have shown that the endemic New Zealand mistletoe Peraxilla tetrapetala (Loranthaceae) is frequently pollen limited. This plant species is dependent for pollination upon endemic honeyeater birds (Ladley \& Kelly 1995) and endemic solitary bees (Kelly et al. 1996; Robertson et al. 2005). A shortage of visits by pollinators means that natural fruit set rates are often less than half that for hand-pollinated flowers. Robertson et al. (1999) showed that the result was not confounded by cryptic self-incompatibility within plants or resource reallocation among flowers or among years. Therefore, pollen limitation is well established in P. tetrapetala.

To date, there is no published information on whether reproduction in P. tetrapetala is seed limited. This question was considered by Robertson et al. (1999) who argued that seed limitation seemed likely because of features of the biology of the species. Such inferences are, however, no substitute for empirical testing.

In this paper we tested, with two replicated sites, whether augmenting the seed supply for P. tetrapetala leads to increased numbers of surviving seedlings after 4-6 years. Because natural seedlings of P. tetrapetala are sparse, cryptic, and often in the inaccessible upper canopy, it was not practical to compare the density of seedings in control plots with the density of seedlings in plots where seeds were added. Therefore, we tested for seed limitation by measuring the strength of compensating density-dependent mortality among seedlings at two densites. If density-dependent mortality is intense, it will reduce the density of surviving seedlings more in high-density plots. This reduces or eliminates the numerical advantage of the higher initial numbers of seeds, and the species may not be seed limited. If density-dependent mortality is weak or absent, then elevated seed numbers will translate into elevated seedling numbers, and the species will be seed limited.

We also simultaneously tested whether $P$. tetrapetala was pollen limited at both study sites during the period of this experiment. If the species is seed limited as well as pollen limited, then the numbers of adult plants will be depressed by the current scarcity of native pollinating animals. This would be a conclusion of some importance for conservation of this declining endemic plant. Alternatively, if the species is pollen limited but not seed limited, the lack of pollinators has much less long-term significance.

\section{MATERIALS AND METHODS}

\section{Study system and sites}

We replicated this study at two sites in Canterbury, eastern South Island, chosen because the mistletoe
P. tetrapetala is common at both. The Ohau site $\left(44^{\circ} 14^{\prime} \mathrm{S} 169^{\circ} 49^{\prime} \mathrm{E}, 540 \mathrm{~m}\right.$ a.s.l.) is in Round Bush, a 5 ha patch of forest on the shore of Lake Ohau. The Craigieburn site $\left(43^{\circ} 09^{\prime} \mathrm{S} 171^{\circ} 43^{\prime} \mathrm{E}, 940 \mathrm{~m}\right.$ a.s.l.) is along the Broken River skifield road in continuous mountain beech forest in the Craigieburn State Forest Park. At both sites mountain beech (Nothofagus solandri var. cliffortioides) is the sole canopy species.

Mistletoes are stem hemiparasites, which has both advantages and disadvantages as a study system for testing seed limitation. There are two advantages. First, mistletoes have a clearly defined establishment site (branches of a suitable host tree), whereas for most plants establishment sites are difficult to define precisely. Peraxilla tetrapetala primarily parasitizes mountain beech, and apparently establishes best on small-diameter branches (less than c. $20 \mathrm{~mm}$ diameter), as shown for the closely related mistletoe Alepis flavida at Craigieburn and for other mistletoe species (Norton et al. 1997; Norton \& Ladley 1998, and references therein).

The second advantage is that germination of P. tetrapetala is insensitive to conditions, so that seeds will germinate after gut passage (or hand removal from the fruit) regardless of substrate (Ladley \& Kelly 1996). This means that seeds will all germinate at various manipulated densities and the resulting effects on establishment and survival can be monitored.

However, there are two disadvantages of mistletoes as a study system. First, survival of seedlings is affected by interactions with the host tree on which they germinate. This includes variation among host trees or host branches which vary in their prior infection with mistletoes. For example, Hoffmann et al. (1986) reported that the presence of one large Tristerix tetrandrus mistletoe prevented further seedlings of that species from establishing on the same host plant, and Sargent (1995) found that host branches were more likely to die if they carried larger numbers of the mistletoe Phoradendron robustissimum (Viscaceae) in tropical America. While these factors are additional complications, they can be allowed for in the experimental design, and are similar to the competitive interactions which affect non-hemiparasitic seedlings.

Second, P. tetrapetala regeneration is wholly dependent on bird dispersal, as gut passage is required to expose the viscin layer which glues the seed to a host branch (Ladley \& Kelly 1996). Intact fruits cannot stick to branches even if they fall off the mistletoe, so undispersed fruits fall to the ground and perish. This means that there is a much less dense 'seedling shadow' around the parent mistletoe, and germinating seedlings are relatively widely dispersed at relatively low densities. The disadvantage of this for studies of seed limitation is that the wide dispersal of germinating seedlings reduces the likely impact of density 
dependence, and makes mistletoes more likely to show seed limitation than 'normal' (less well dispersed) plant species. However, this feature is not unique to mistletoes, but is also shared with non-hemiparasites which experience high mortality near to the parent, for example under the Janzen-Connell model in tropical forests (e.g. Wright 2002; Hyatt et al. 2003).

Therefore, the mistletoes are interesting test cases for seed limitation, but their unusual biology must be considered when assessing the generality of the results.

\section{Pollen limitation}

The flower buds of $P$. tetrapetala are explosive, that is, cannot open without intervention by endemic birds (especially bellbirds, Anthornis melanura: Meliphagidae) and bees (Ladley \& Kelly 1995; Kelly et al. 1996; Robertson et al. 2005). Unless buds are opened by animals, the flower has a very low probability of producing a seed. Consequently, $P$. tetrapetala fruit set is frequently pollen limited; this has been shown for Craigieburn for 1993-2003 (Robertson et al. 1999; Kelly et al. 2004), but for only 2 years in the mid 1990s at Ohau (Robertson et al. 1999; Montgomery et al. 2003; Robertson et al. 2005). Therefore, we quantified pollen limitation at Ohau and Craigieburn during the course of the seed-limitation experiment, as it is important to measure both at the same time (Ashman et al. 2004).

Pollen limitation was tested using previously published methods (Kelly et al. 2004). Briefly, we measured fruit set ( $\%$ of flowers ripening into a single-seeded fruit) under three treatments. 'Natural' flowers were unmanipulated and accessible to pollinators. 'Hand-pollinated' flowers were individually pollinated when receptive with a paintbrush carrying a mixture of pollen from several other mistletoe plants. 'Bagged' flowers were enclosed in muslin bags before they had opened to prevent any pollinator visitation. All three treatments were performed on the same plants.

The results were analysed within each year using a binomial Generalized Linear Model (GLM) run in S-Plus version 4.5 (Mathsoft, Inc., Seattle, Washington, USA). Predictors were plant (as a block effect entered first), and treatment. When treatment was significant, a post hoc means test compared natural and hand-pollinated treatments with test for significant pollen limitation.

As a measure of effect size, for each year we calculated the Pollen Limitation Index (PLI) of Larson and Barrett (2000) based on fruit set, that is, (1 - (natural/ hand-pollinated)), truncated at zero. A PLI of 0 indicates no pollen limitation, while a PLI of 1.0 indicates complete pollen limitation.

\section{Seed limitation}

At both sites mistletoe fruits ripen in autumn (Kelly et al. 2004). The Ohau seed-augmentation experiment was set up in March 2000 and monitored until December 2005 (69 months), while Craigieburn was sown 2 years later (May 2002) due to low fruit crops in the 2000 and 2001 seasons and followed till November 2005 (42 months). At each site ripe fruits were collected locally from $>20$ parent plants and mixed before sowing.

We planted mistletoe seeds by hand onto suitable host branches at two densities, where the relevant scale for density was defined as the number of mistletoes per branch segment. Observations at the sites showed that naturally dispersed mistletoe seeds were rare, but when found they usually occurred singly on a branch. The low-density treatment imitated natural densities by placing single seeds onto sections of branch, but we used three seeds in total per branch with $15 \mathrm{~cm}$ between seeds. We used three seeds per branch to ensure an adequate total number of seeds within the limited number of available branches, on the assumption that the $15 \mathrm{~cm}$ spacing would minimize any interaction among adjacent seeds within the first few years, as these mistletoes are very slow-growing (Ladley \& Kelly 1996, and Results section). The high-density treatment used 20 seeds per branch in four clumps of five at $15 \mathrm{~cm}$ spacings. In the high-density clumps, the five seeds were placed touching each other (Fig. 1), a

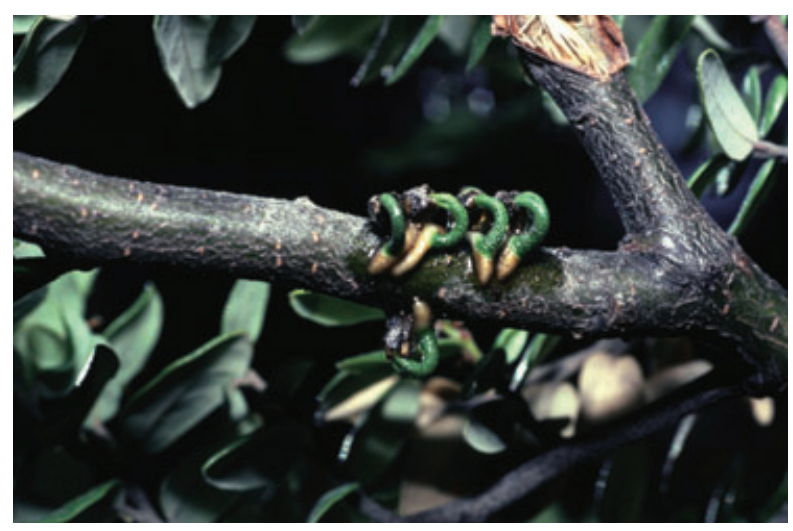

Fig. 1. A high-density sown clump of five seedlings of the mistletoe Peraxilla tetrapetala on a host branch of Nothofagus solandri var. cliffortioides at Ohau, nine months after planting. The seedlings were planted on the upper side touching each other, but one slid under the branch before the viscin hardened. The dark glossy area on the bark around the seeds is cement secreted later by the seed and holdfast. All the seeds have put out a radicle (which is green and photosynthetic) ending in a holdfast against the branch which attempts to develop a haustorial connection. Three of the seedlings (bottom, top second left, top right) are about to pull their cotyledons out of the seed coat. For scale the branch is about $7 \mathrm{~mm}$ diameter. 
higher local density than we have ever observed naturally.

At each site 10 healthy host trees were chosen. On each tree 12 young healthy small-diameter outer branches within $3 \mathrm{~m}$ of the ground were tagged and randomly assigned to one of two treatments. There were 10 low-density and 2 high-density branches per tree, giving 30 low-density and 40 high-density seeds for each tree $\times 10$ trees per site. At Ohau, four of the 10 hosts had prior infection with $P$. tetrapetala mistletoes, while none of the plants at Craigieburn did, so trees from Ohau were used to test for any impact of prior infection.

Hand-sowing of $P$. tetrapetala seeds involves removing the seed from the fruit skin to expose the viscin layer, and placing the seed onto a branch (Norton et al. 2002). The sticky viscin holds the seed on the branch, and hardens over the first few days, gluing the seed in place. A minority of seeds fall off, probably mostly before the viscin has hardened. In New Zealand there are no published reports of seed predators known to remove mistletoe seeds from branches.

After planting, the sites were checked annually in summer. The fate of each seed could be determined as once the viscin has hardened, even dead seeds and seedlings persist on the host branches. Out of 240 branches, one (a low-density branch at Ohau) was damaged by cattle during the experiment and had to be excluded. Three fates were recognized: fell off, adhered but died, and alive. The 'alive' category included both established seedlings (those which had formed a haustorial connection to the host xylem and put out a shoot with true leaves), and germinated but nonestablished seedlings, which rely on rainfall for water and the radicle for photosynthesis (Fig. 1), for up to several years (Ladley \& Kelly 1996). The few seedlings which established then died ( 9 at Ohau and 2 at Craigieburn) were not included in the live total. For live seedlings we recorded the number of true leaves (which is zero for nonestablished seedlings).

Analysis of survival used binomial GLMs run in S-Plus. The effect of prior infection of hosts was tested using a single-factor GLM on overall survival versus host presence/absence of existing mistletoes, using only the Ohau data. Next using both sites we did three GLMs with site, density and site $\times$ density as predictors, and trees as replicates. The first GLM tested the probability of seeds falling off (failing to adhere to the branch), and the second tested the probability of adhered seeds surviving until the end of the experiment. The third GLM analysed the overall product of the previous two stages, that is, number alive at the end compared with the number of seeds sown.

Analysis of the effect of density on final size of surviving plants used the number of true leaves per seedling as the response variable. This was tested against whether there were any living conspecifics in the target seedling's clump (so solitary seeds, and clumped seeds which were the sole survivor of their clump, were compared with seedlings in clumps with 2 or more surviving seedlings). Leaf number was tested against site and the presence/absence of neighbours using a Poisson GLM run in S-Plus. Leaf number was also tested against initial density (high vs. low).

\section{RESULTS}

\section{Pollen limitation}

In all 7 years at Ohau there were significant differences in fruit set among the pollination treatments; there was also usually a plant effect (Table 1a). Natural fruit set was always much less than hand-pollinated fruit set (means of $29.9 \%$ and $74.7 \%$, respectively; Fig. 2a), and post hoc comparisons showed these means to differ significantly in five of the 7 years (Table 1a). Over this time the mean PLI was 0.62 (range among years 0.38 0.84 ). A similar pattern was found at Craigieburn, where the most recent 2 years (Fig. 2b, Table 1b) continued trends previously published to 2003 (Kelly et al. 2004). In total, post hoc comparisons found significant differences between natural-pollinated and hand-pollinated fruit set rates in 7 of 12 years at Craigieburn. The overall means were $35.4 \%$ for natural and $66.7 \%$ for hand-pollinated flowers, and the PLI averaged 0.44 (range 0.18-0.81). All this shows frequent, strong pollen limitation at both sites before and during the course of the seed limitation experiment, which reduced the number of seeds produced by around half.

\section{Seed limitation}

There was no detectable effect of either prior mistletoe infection in hosts, or of preferential branch death in response to mistletoe density. At Ohau, survival of planted mistletoes did not differ between the four hosts with established $P$. tetrapetala plants versus the six hosts without $\left(F_{1,18}=0.016, P=0.899\right)$. Only two branches died during the study (one high density and one low density, on the same plant in the last year at Ohau).

At both sites, most seeds that germinated, and nearly all seeds that fell off, had done so by the first revisit (9-10 months after planting). In contrast, establishment often took several years. By the end of the experiment, 63 of the 81 live plants (78\%) were established, and the rest had germinated but not yet established.

When testing the chance of seeds adhering to the branch, and of surviving till the end of the study, 
Table 1. Significance tests for pollen limitation of fruit set of Peraxilla tetrapetala at (a) Ohau and (b) Craigieburn, from binomial GLMs

\begin{tabular}{|c|c|c|c|c|}
\hline Year & $n$ plants & $\begin{array}{l}\text { Plant effect } \\
\text { (\% deviance) }\end{array}$ & $\begin{array}{l}\text { Treatment effect } \\
\text { (\% deviance })\end{array}$ & $\begin{array}{l}\text { Significance hand } \\
\text { versus natural }\end{array}$ \\
\hline \multicolumn{5}{|c|}{ (a) Ohau } \\
\hline 1997 & 10 & $12.3^{\star}$ & $77.2^{\star \star \star}$ & $\star \star$ \\
\hline 1998 & 14 & $30.1^{\star \star \star}$ & $53.8^{\star \star \star}$ & $\star \star$ \\
\hline 1999 & 9 & $24.8 \mathrm{NS}$ & $64.8^{\star \star \star}$ & NS \\
\hline 2000 & 10 & $40.9^{\star \star \star}$ & $51.0^{\star \star \star}$ & NS \\
\hline 2001 & 10 & $34.6^{\star \star}$ & $59.0^{\star \star \star}$ & $\star$ \\
\hline 2002 & 10 & $10.7 \mathrm{NS}$ & $77.4^{\star \star \star}$ & $\star \star \star$ \\
\hline 2003 & 10 & $31.0^{\star \star \star}$ & $65.2^{\star \star \star}$ & $\star \star \star$ \\
\hline \multicolumn{5}{|c|}{ (b) Craigieburn } \\
\hline 2004 & 5 & $61.6^{\star \star}$ & $34.6^{\star}$ & $\star \star$ \\
\hline 2005 & 10 & $47.2^{\star \star \star}$ & $43.3^{\star \star \star}$ & NS \\
\hline
\end{tabular}

${ }^{\star} P<0.05 ;{ }^{\star \star} P<0.01 ;{ }^{\star \star \star} P<0.001$. 'Year' indicates the year of the austral autumn, so '1997' represents the fruits set from the 1996/97 summer in autumn 1997. For significance tests for Craigieburn up to 2003, see Kelly et al. (2004). Predictors were plant (entered first), then treatment (hand-pollinated, natural, or bagged). Post hoc means tests were run comparing natural versus hand treatments. NS, not significant.
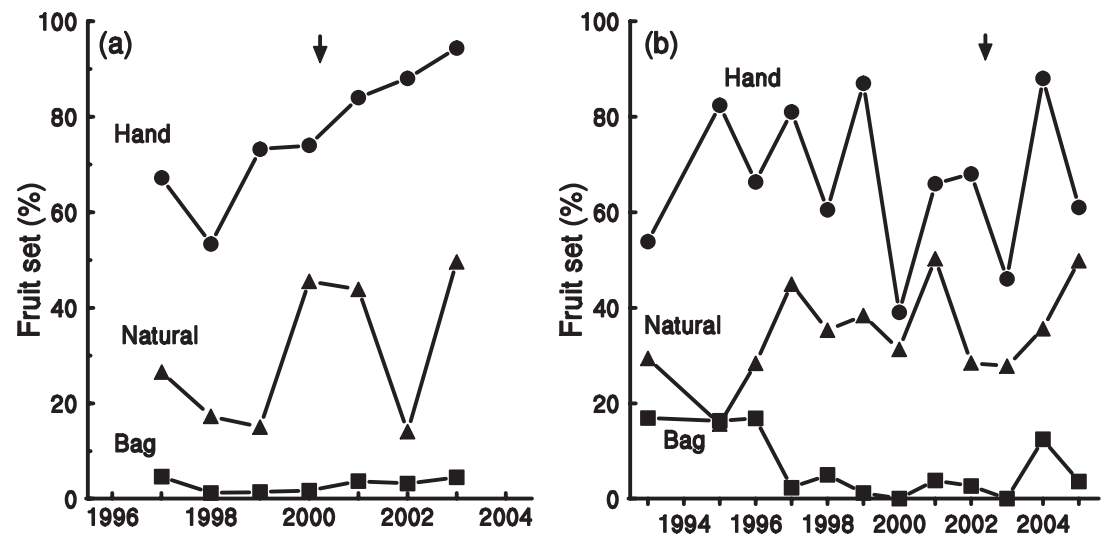

Fig. 2. Pollination limitation of fruit set in Peraxilla tetrapetala at (a) Ohau over 7 years and (b) Craigieburn during 12 years. The time when the seed-sowing experiments were set up is shown with an arrow on each graph. The Craigieburn data up till 2003 were published previously (Kelly et al. 2004) and are repeated here to show context. The treatments differed significantly in all years except 1993 at Craigieburn, and natural (unmanipulated) flowers usually had significantly lower fruit set than handpollinated flowers, see Table 1. '1997' refers to the 1996/97 season.

there was no significant effect of site or of the site $\times$ treatment interaction in any of the three GLMs (Table 2). The density effect was significant only for adhesion (Table 2a), with high-density seeds being only half as likely to fall off the branch ( $8.6 \%$ fell off) as low-density seeds (18.1\%). For survival of adhered seeds, there was slightly higher survival at lower density but the effect was non-significant $(P=0.083)$. When adhesion and survival were combined, the overall survival of seeds throughout the experiment was not significantly different between high and low density $(P=0.146$, Table $2 c)$. The time course of survival (Fig. 3) showed a slow increase in the gap between low and high density survival over time but there was still substantial overlap in the error bars. Overall, there was a significant initial benefit to high- density seeds, followed by a weak and non-significant suggestion of lower survival at high density.

\section{Density of surviving seedlings at end of experiment}

During the 6 years of the study, we found only a single naturally deposited mistletoe seed arrive at the branches to alter the sown densities (in the last year at Ohau). By the end of the experiment, because of high mortality rates, most surviving seedlings were no longer in high-density situations; that is, most were the sole living plant in their clump whether or not they began at high or low density. Across both sites, there were 81 surviving seedlings, of which 43 had started in 
Table 2. Survival of $P$ tetrapetala seeds sown at two densities at Ohau over 69 months, and Craigieburn over 42 months

\begin{tabular}{|c|c|c|c|c|c|}
\hline Analysis & Factor & d.f. & Deviance & $F$ & $P$ \\
\hline \multirow[t]{4}{*}{ (a) Adhered } & Site & 1 & 3.54487 & 1.203 & 0.280 \\
\hline & Density & 1 & 27.50657 & 9.333 & 0.004 \\
\hline & Site $\times$ density & 1 & 6.47946 & 2.199 & 0.147 \\
\hline & Residual & 36 & 116.9826 & & \\
\hline \multirow[t]{4}{*}{ (b) Survival if adhered } & Site & 1 & 6.892969 & 3.782 & 0.060 \\
\hline & Density & 1 & 5.809276 & 3.187 & 0.083 \\
\hline & Site $\times$ density & 1 & 0.017470 & 0.009 & 0.923 \\
\hline & Residual & 36 & 72.20238 & & \\
\hline \multirow[t]{4}{*}{ (c) Overall survival } & Site & 1 & 5.938409 & 3.480 & 0.070 \\
\hline & Density & 1 & 3.759134 & 2.203 & 0.146 \\
\hline & Site $\times$ density & 1 & 0.000325 & 0.0002 & 0.989 \\
\hline & Residual & 36 & 68.06013 & & \\
\hline (d) Means by density & Survival, high density & Survival, low density & & & \\
\hline Adhered & 0.914 & 0.819 & & & \\
\hline Survival if adhered & 0.053 & 0.087 & & & \\
\hline Overall survival & 0.048 & 0.072 & & & \\
\hline
\end{tabular}

Three stages are each tested with a binomial GLM, using trees as replicates (10 per site), and using treatment (high vs. low density plantings within the tree) and site (Ohau vs. Craigieburn) as predictors. (a) Probability of a sown seed adhering to the branch; (b) probability of an adhered seed surviving to the end of the study; (c) overall chance of survival from time of sowing to the end $(=a \times b)$. (d) The mean suvival probabilities for parts $(a-c)$ at low and high densities. Significant effects are in bold type.

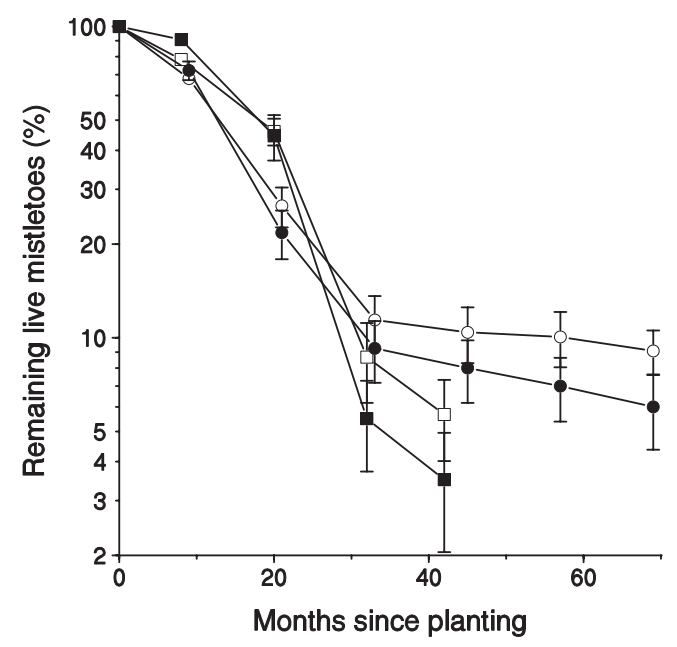

Fig. 3. Mean percentage survival (mean \pm SEM) versus time for high-density (filled symbols) and low-density (hollow symbols) seeds and seedlings of Peraxilla tetrapetala sown at two different sites, Ohau (circles) and Craigieburn (squares). At both sites, high-density seeds had a small initial advantage by being significantly more likely to stick to the branch, but by the end of the experiment there was no density effect on overall survival rates (see Table 2 for statistics).

the low-density treatment, 12 were the sole survivor in a clump of five, and 26 were in a clump with a living neighbour. The mean number alive per 5 -seeded clump with a living plant was 1.75 seedlings at
Table 3. Effect of site (Ohau vs. Craigieburn) and surviving neighbouring seedlings in the same clump (none $v s$. some) on number of true leaves per surviving Peraxilla tetrapetala seedling at the end of the experiment

\begin{tabular}{lrrrc}
\hline Factor & d.f. & Deviance & $F$ & $P$ \\
\hline Site & 1 & 500.68 & $\mathbf{8 . 0 0}$ & $\mathbf{0 . 0 0 6}$ \\
Neighbours & 1 & 15.23 & 0.24 & 0.623 \\
Site $\times$ Neighbours & 1 & 3.54 & 0.05 & 0.812 \\
Residual & 77 & 2916.93 & & \\
\hline
\end{tabular}

The analysis used a Poisson GLM with a log link function. Significant effects are in bold type.

Craigieburn after 42 months, and 1.50 seedlings at Ohau after 69 months. So at the end of this experiment, densities had reduced to the point where further density-dependent effects on subsequent growth and survival would be expected to be small.

\section{Size of surviving seedlings}

Seedling growth rates were slow, as is normal in this species. Surviving plants at the longer-running site (Ohau) after 69 months averaged only $6 \times 6 \times 5 \mathrm{~cm}$ in size, while the largest plant there had 318 leaves and was $50 \times 40 \times 35 \mathrm{~cm}$. There was no indication of any reduction in seedling growth rate in seedlings which 
had some immediate neighbours (i.e. another surviving seedling in the same clump). While plants at Ohau had significantly more leaves than plants at Craigieburn (site effect in Table 3; means 25.5 leaves at Ohau and 5.5 at Craigieburn), there was no significant effect of neighbours on number of leaves per plant and no site $\times$ neighbours interaction (Table 3 ). There was also no significant difference in final number of leaves when survivors were classified by their original (sown) density (analysis not shown).

\section{DISCUSSION}

\section{Limitations of the experiment}

While our data suggest both pollen limitation and seed limitation in $P$. tetrapetala, there are some limitations to our study which must be considered. First, we did not follow the sown plants to reproductive age, but only to an age of 42-69 months, at which stage all were still small (the largest seedling had 318 leaves and was $50 \times 40 \times 35 \mathrm{~cm}$ in size, and the mean at Ohau was only $6 \times 6 \times 5 \mathrm{~cm})$. The minimum age observed for P. tetrapetala to begin to flower is 4 years for a mistletoe we planted on the University campus, but probably is some years longer under field conditions. However, while survival of these young plants to flowering age is not assured, they probably have as good a chance as naturally occurring sparsely distributed seedlings, so the additional seed sown has increased the pool of potential recruits into the next generation.

Another question is whether our sown densities were realistic. From field observations at the site, the low density is similar to natural densities at the relevant scale of the immediate surroundings given that a seed is present (especially given the absence of any evidence of mistletoe-induced branch mortality, so that each low-density seedling was probably unaffected by any other mistletoe). The high density treatment was much higher (five seeds in a single clump), which would increase the likelihood of strong density-dependent effects. Therefore, our high-density treatment can be taken as a worst case.

\section{Is $P$. tetrapetala pollen limited and seed limited?}

This paper establishes that $P$. tetrapetala was strongly pollen limited at both the Craigieburn and Ohau sites, and the absence of strong density-dependent competition among seedlings suggests that it was also seed limited at both sites over the same time period. Three factors indicate that density dependence was not strong enough to prevent seed limitation from occurring. First, despite the high density (fivefold higher per clump) any density-dependent decrease in survival was not consistent enough to be significant at $P<0.05$. Second, even if the non-significant decrease in survival at high density was real (which we do not claim to have demonstrated), its magnitude was not great - an approximately $40 \%$ reduction in survival (from $8.7 \%$ to $5.3 \%$ ) for adhered seeds. Third, any effect of this putatively lower survival was offset by the (highly significant) higher adhesion at high densities, so that the net difference in means over 4-6 years was only $33 \%$ lower survival at high density $(4.8 \%$ vs. $7.2 \%)$. This reduced overall survival at higher densities was again non-significant, but even if it had been significant was too small an effect to prevent higher seed densities from generating more $4-6$ years old seedlings - the core test for seed limitation.

By the end of our study, two-thirds of the surviving seedlings were alone at their spot on the branch, and most of the rest had only a single neighbour at their point of attachment. These densities per clump are comparable to those reported for naturally occurring seedlings of the loranthaceous mistletoe Amyema preissii in central Australia (Reid \& Smith 2000). Thus, density-dependent effects are likely to continue to be weak beyond the end of our study period.

Therefore, if pollen limitation was alleviated, more seeds would be produced (Robertson et al. 1999). Because mistletoe fruits are highly preferred and efficiently taken by birds (Murphy \& Kelly 2001; Kelly et al. 2004), the extra seeds should nearly all get dispersed. The chances of a defecated seed landing on a host branch must be rather small, as there is no directed placement of seeds onto branches (cf. Reid 1991). Nevertheless, we have no reason to suspect that the per-seed chance of landing on a branch is reduced at higher seed densities. Therefore, more seeds ripened should mean more seeds landing on branches and more plants in the next generation.

Ashman et al. (2004) found no published examples where a single plant species had been tested by pollen augmentation and seed augmentation at the same time. Here we have done so and shown that P. tetrapetala appears to be simultaneously pollen limited and seed limited. This has two consequences, for conservation and for ecology.

The conservation implications are that, if $P$. tetrapetala is both pollen limited and seed limited, the service provided by pollinating birds does affect plant densities. Peraxilla tetrapetala is a nationally declining endemic species which has suffered greatly from various human impacts, including forest clearance, predation by introduced mammalian herbivores like the Australian brushtail possum (Trichosurus vulpecula), and loss of avian pollinators due to predation by mammalian carnivores (Ogle \& Wilson 1985; Norton 1991; Robertson et al. 1999; Craig et al. 2000; Sessions \& Kelly 2001; Sessions et al. 2001). This 
study shows that manipulations which increase the density of pollinating birds, such as trapping carnivores (Kelly et al. 2005), should have an effect on the number of adult mistletoe plants.

The ecological implications are that we have shown for $P$. tetrapetala that pollinator activity should feed through to affect adult plant densities, a finding not previously shown for any species (Ashman et al. 2004), and shown here over many years at two replicate sites. This finding may be dependent on the biology of our species, whereby there is not a dense 'seedling shadow' under parent mistletoes; other plant species may behave differently. Similar studies on plant species with a range of life histories would clearly be desirable. Meantime, we can say that for this endemic mistletoe, mutualisms do matter (sensu Bond 1994).

\section{ACKNOWLEDGEMENTS}

We thank the Department of Conservation for access to the study sites, the Public Good Science Fund for supporting this research under contract CO9X0004, and Gary Houliston and Matt Walters for field assistance.

\section{REFERENCES}

Ashman T.-L., Knight T. M., Steets J. A. et al. (2004) Pollen limitation of plant reproduction: ecological and evolutionary causes and consequences. Ecology 85, 2408-21.

Bond W. J. (1994) Do mutualisms matter? Assessing the impact of pollinator and disperser disruption on plant extinction. Phil. Trans. R. Soc. Lond. B 344, 83-90.

Burd M. (1994) Bateman's principle and plant reproduction the role of pollen limitation in fruit and seed set. Bot. Rev. 60, 83-139.

Craig J., Anderson S., Clout M. et al. (2000) Conservation issues in New Zealand. Annu. Rev. Ecol. Syst. 31, 61-78.

Hoffmann A. J., Fuentes E. R., Cortes I., Liberona F. \& Costa V. (1986) Tristerix tetrandrus (Loranthaceae) and its host plants in the Chilean matorral; patterns and mechanisms. Oecologia 69, 202-6.

Hyatt L. A., Rosenberg M. S., Howard T. G. et al. (2003) The distance dependence prediction of the Janzen-Connell hypothesis: a meta-analysis. Oikos 103, 590-602.

Kelly D., Ladley J. J., Robertson A. W., Edwards J. \& Smith D. C. (1996) The birds and the bees. Nature 384, 615.

Kelly D., Ladley J. J. \& Robertson A. W. (2004) Is dispersal easier than pollination? Two tests in New Zealand Loranthaceae. N. Z. F. Bot. 42, 89-103.

Kelly D., Brindle C., Ladley J. J. et al. (2005) Can stoat (Mustela erminea) trapping increase bellbird (Anthornis melanura) populations and benefit mistletoe (Peraxilla tetrapetala) pollination? N. Z. F. Ecol. 29, 69-82.

Knight T. M., Steets J. A. \& Ashman T.-L. (2006) A quantitative synthesis of pollen supplementation experiments highlights the contribution of resource reallocation to estimates of pollen limitation. Am. F. Bot. 93, 271-7.

Knight T. M., Steets J. A., Vamosi J. C. et al. (2005) Pollen limitation of plant reproduction: pattern and process. Annu. Rev. Ecol. Evol. Syst. 36, 467-97.

Ladley J. J. \& Kelly D. (1995) Explosive New Zealand mistletoe. Nature 378, 766.

Ladley J. J. \& Kelly D. (1996) Dispersal, germination and survival of New Zealand mistletoes (Loranthaceae): dependence on birds. N. Z. F. Ecol. 20, 69-79.

Larson B. M. H. \& Barrett S. C. H. (2000) A comparative analysis of pollen limitation in flowering plants. Biol. $\mathcal{F}$. Linnean Soc. 69, 503-20.

Montgomery B. R., Kelly D., Robertson A. W. \& Ladley J. J. (2003) Pollinator behaviour, not increased resources, boosts seed set on forest edges in a New Zealand Loranthaceous mistletoe. N. Z. F. Bot. 41, 277-86.

Murphy D. J. \& Kelly D. (2001) Scarce or distracted? Bellbird (Anthornis melanura) foraging and diet in an area of inadequate mistletoe pollination. N. Z. F. Ecol. 25, 69-81.

Norton D. A. (1991) Trilepidea adamsii: an obituary for a species. Cons. Biol. 5, 52-7.

Norton D. A. \& Ladley J. J. (1998) Establishment and early growth of Alepis flavida in relation to Nothofagus solandri branch size. N. Z. F. Bot. 36, 213-7.

Norton D. A., Ladley J. J. \& Owen H. J. (1997) Distribution and population structure of the loranthaceous mistletoes Alepis flavida, Peraxilla colensoi and Peraxilla tetrapetala within two New Zealand Nothofagus forests. N. Z. F. Bot. 35, 323-36.

Norton D. A., Ladley J. J. \& Sparrow A. D. (2002) Host provenance effects on germination and establishment of two New Zealand mistletoes (Loranthaceae). Funct. Ecol. 16, 657-63.

Ogle C. \& Wilson P. (1985) Where have all the mistletoes gone? Forest Bird 237, 10-3.

Reid N. (1991) Coevolution of mistletoes and frugivorous birds? Aust. F. Ecol. 16, 457-69.

Reid N. \& Smith M. S. (2000) Population dynamics of an arid zone mistletoe (Amyema preissii, Loranthaceae) and its host Acacia victoriae (Mimosaceae). Aust. F. Bot. 48, 45-58.

Robertson A. W., Kelly D., Ladley J. J. \& Sparrow A. D. (1999) Effects of pollinator loss on endemic New Zealand mistletoes (Loranthaceae). Cons. Biol. 13, 499-508.

Robertson A. W., Ladley J. J. \& Kelly D. (2005) The effectiveness of short-tongued bees as pollinators of apparently 'ornithophilous' New Zealand mistletoes. Aust. Ecol. 30, 298-309.

Sargent S. (1995) Seed fate in a tropical mistletoe: the importance of host twig size. Funct. Ecol. 9, 197-204.

Sessions L. A. \& Kelly D. (2001) Heterogeneity in vertebrate and invertebrate herbivory and its consequences for New Zealand mistletoes. Aust. Ecol. 26, 571-81.

Sessions L. A., Rance C., Grant A. \& Kelly D. (2001) Possum (Trichosurus vulpecula) control benefits native beech mistletoes (Loranthaceae). N. Z. F. Ecol. 25, 27-33.

Turnbull L. A., Crawley M. J. \& Rees M. (2000) Are plant populations seed-limited? A review of seed sowing experiments. Oikos 88, 225-38.

Wright S. J. (2002) Plant diversity in tropical forests: a review of mechanisms of species coexistence. Oecologia 130, 1-14.

Zimmerman M. \& Pyke G. H. (1988) Reproduction in Polemonium: assessing the factors limiting seed set. Am. Nat. 131, 723-38. 